\title{
Specific features of endoscopic dacryocystorhinostomy - case report
}

\author{
Lucian Lapusneanu', Alina Neacsu' ${ }^{2}$, Andreea Naca ${ }^{3}$ \\ ${ }^{1}$ ENT Department, Braila Emergency County Hospital, Braila, Romania \\ ${ }^{2}$ Department of Ophthalmology, Braila Emergency County Hospital, Braila, Romania \\ ${ }^{3}$ Department of Radiology and Medical Imaging, Braila Emergency County Hospital, Braila, Romania
}

\begin{abstract}
OBJECTIVE. The aim of the study was to evaluate the endoscopic dacryocystorhinostomy (DCR) with some particularities and its advantages over external DCR.

MATERIAL AND METHODS. We evaluated 3 female patients (age range 35-84 years) diagnosed with chronic dacryocystitis lacrimal sac abscess (2 cases) and lacrimal sac fistula (1 case). All patients presented a history of repeated episodes of acute dacryocystitis initially treated with broad spectrum antibiotics by the ophthalmologist. The evaluation protocol consisted in cranio-facial CT scan or MRI for the evaluation of the lacrimal sac and nasal structures, an ophthalmologic examination with the catheterization of the superior and inferior lacrimal punctum with a light probe to verify the permeability of the lacrimal pathway, and the Jones test with fluorescein to receive information about the common lacrimal path. Lacrimal syringing with regurgitation of fluid from the opposite punctum was the only criteria to decide the surgery. In all three cases we performed an endoscopic DCR, with stent insertion in two cases and a laco-dacryo-rhinostomy in one case. In only one case a reintervention was needed 12 months later.
\end{abstract}

CONCLUSION. The endoscopic DCR, with its different particularities, is a safe surgical procedure with a low rate of complications, being the treatment of choice for the treatment of nasolacrimal duct obstruction.

KEYWORDS: endoscopic dacryocystorhinostomy, lacrimal sac, fluorescein test.

\section{INTRODUCTION}

Dacryocystorhinostomy (DCR) represents the correction of the nasolacrimal duct obstruction. The first dacryocystectomy was performed by Celsus in $50 \mathrm{AD}$. In 1893, Caldwell first introduced the endonasal approach for lacrimal surgery and later, during the beginning of 1900, Mosher performed the same surgical technique $^{1}$. In contrast to the external approach performed through a cutaneous incision to access the lacrimal sac, the endonasal procedure gained popularity due to its efficacy and relatively low complication rates $^{2}$.

In 1989, McDonogh was the first to describe the endoscopic dacryocystorhinostomy. The introduction of rigid nasal endoscopes and later on the new endoscopy instruments with direct guidance raised up the interest to perform the endonasal approach of the lacrimal sac.

This surgical technique avoids an external scar, preserves the lacrimal pump system, offers the possibility of treating any associated intranasal pathology and preserves the lacrimal sac mucosa $a^{1,3,4}$.

In this article we want to present our experience with endoscopic DCR and evaluate this technique with some particularities and its advantages over external DCR.

\section{CASE REPORT}

We present 3 cases of dacryocystitis in which we performed endoscopic DCR. The differences between the surgical techniques consisted in the degree of the lacrimal sac opening and the manner in which we decided to maintain the drainage of the lacrimal sac into the nasal fossa. In one case we conducted a wide opening of the lacrimal sac, for the second we used a silicone stent to maintain the patency of the drainage pathway and in the third case a venous catheter that made a communication between the caruncular region and the nasal cavity (laco-dacryo-rhinostomy). 


\section{Common surgical steps}

The ophthalmologist catheterized the inferior and superior lacrimal puncta with alighted probe to verify the permeability of the lacrimal drainage. The Jones Test with fluorescein was used, giving information about the common lacrimal channel. The lacrimal sac syringe with regurgitation of fluid from the opposite puncta was the only criteria to decide the surgery.

In all three cases the surgical procedure was performed under general anaesthesia. The nose was packed for 7 minutes with soak cottons in a solution containing $3 \mathrm{ml}$ naphazoline hydrochloride $0.1 \%$ and $2 \mathrm{ml}$ lidocaine $1 \%$. A 0 degree endoscope, $4 \mathrm{~mm}$ in diameter, was used. Local infiltrations with 1\% lidocaine and 1:100,000 epinephrine solutions, in the region of the anterior attachment of the middle turbinate, were made.

The next step consisted in the endoscopic identification of the lacrimal sac. The anatomic landmark for identifying the position of the lacrimal sac is repre- sented by the insertion of the root of the middle turbinate on the lateral nasal wall and the maxillary line. In those patients with a changed nasal anatomy due to previous nasal surgeries, the use of a fiberoptic endoilluminator can be of great help. We performed this investigation in all three cases. The 20-gauge illuminated fiberoptic light probe was advanced gently through the lower canaliculus into the lacrimal sac, the light being located under endoscopic examination on the lateral wall of the nasal cavity. The location corresponded to the posterior end of the lacrimal sac (Figure 1a,b).

The lateral wall mucosa was incised with a sickle knife and was elevated using a Freer elevator. To allow an adequate exposure of the lacrimal bone, the incision was made vertically, from inferior to superior, anterior to the sac location (Figure 2). We preserved the flaps of the mucosa and we used them to cover the exposed bone in two cases (Figure 3).

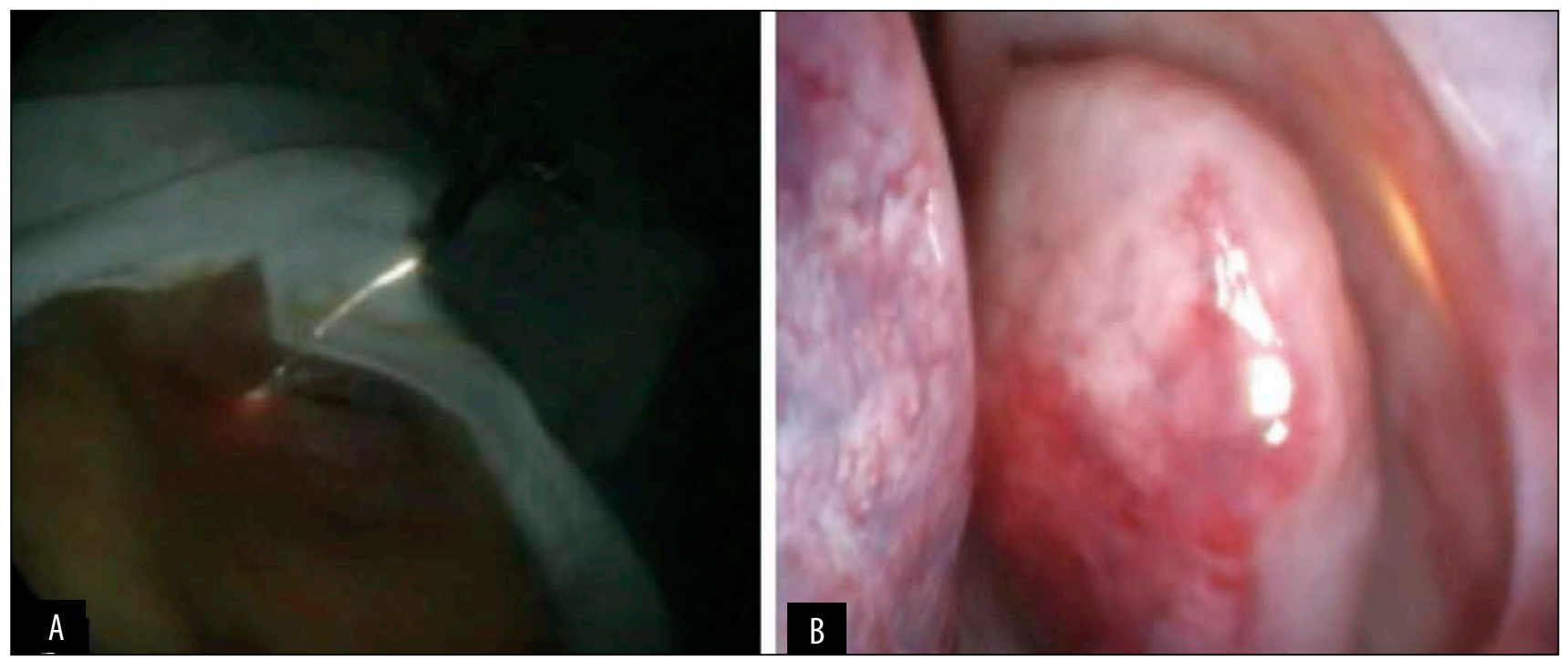

Figure 1 Fibreoptic endoilluminator examination: A. External view of the light probe; $\mathbf{B}$. Nasal endoscopy revealing the position of the lacrimal sac on the lateral wall of the nasal fossa

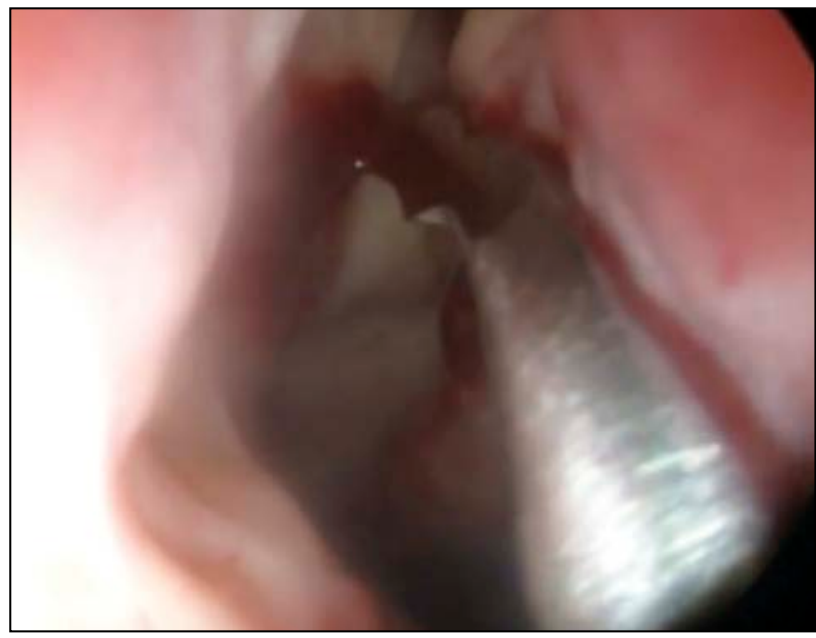

Figure 2 Intraoperatory view - incision of the lateral wall mucosa

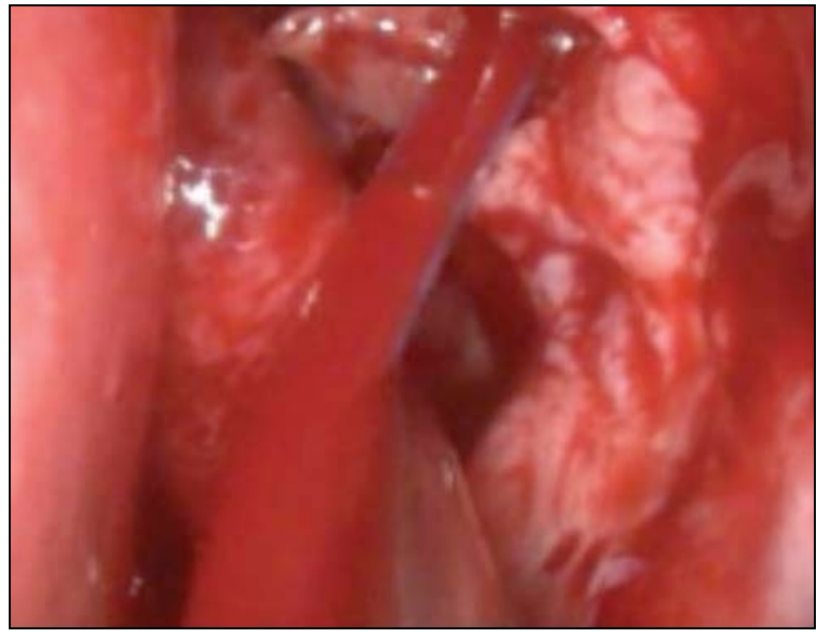

Figure 3 Intraoperatory view - preserved flaps of the mucosa to cover the exposed lacrimal bone 
To expose the lacrimal sac, the bone must be removed. This procedure was performed using a drill for the first case (Figure 4) and a Kerrison's punch and a drill for the other two (Figure 5). The bone removal should start from the maxillary line and performed anteriorly.

After bone removal, the lacrimal sac was incised using a sickle knife and in all cases the purulent content was evacuated (Figure 6).

\section{Specific surgical steps}

Case 1. 84-year-old female patient presenting a swelling, redness and pain in the inner corner of the left eye, epiphora and purulent secretions (Figure 7a); the coronal CT scan section through the anterior sinuses showed a well-demarcated cystic lesion, rounded, homogeneous in the superior half of the nasolacrimal duct on the left side, extending between the lateral nasal process and the maxillary prominence (Figure $7 \mathrm{~b}$ ).

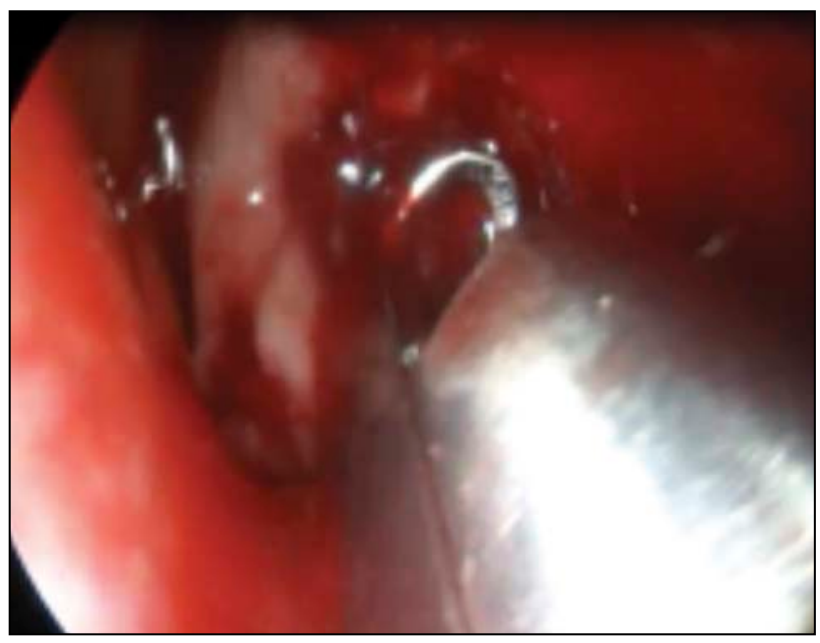

Figure 5 Intraopertory view - bone removal by using the Kerrison's punch

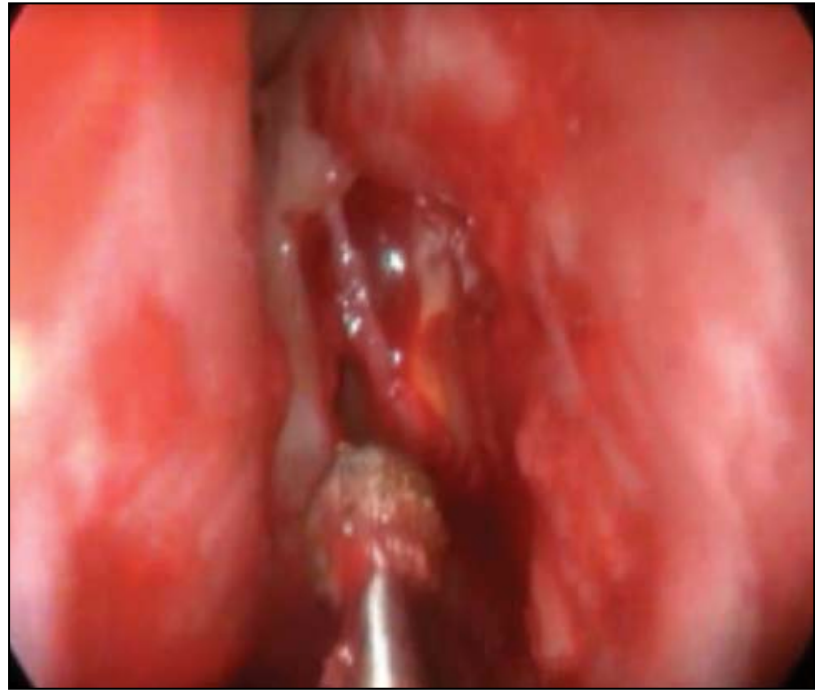

Figure 4 Intraoperatory view - bone removal by drilling

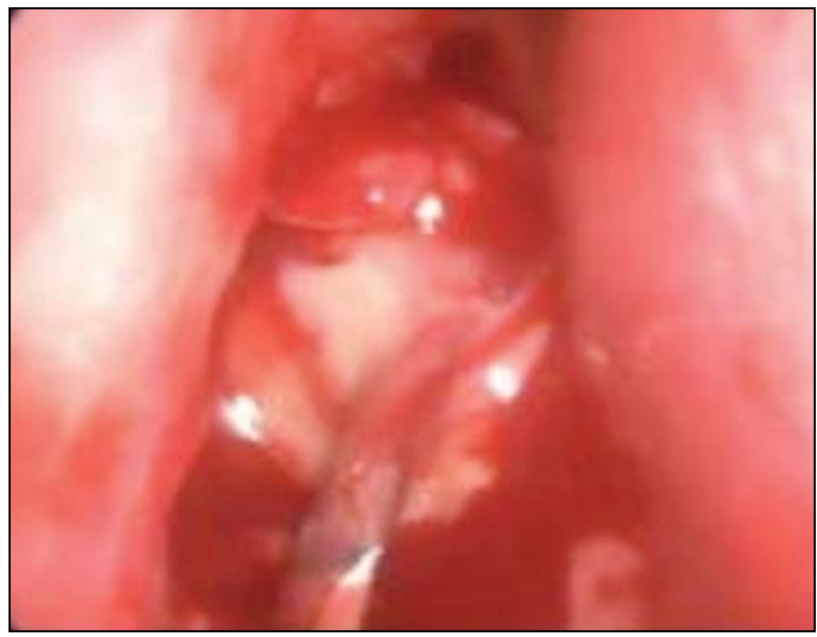

Figure 6 Exposure and incision of the lacrimal sac; evacuation of purulent secretions (intraoperatory view)

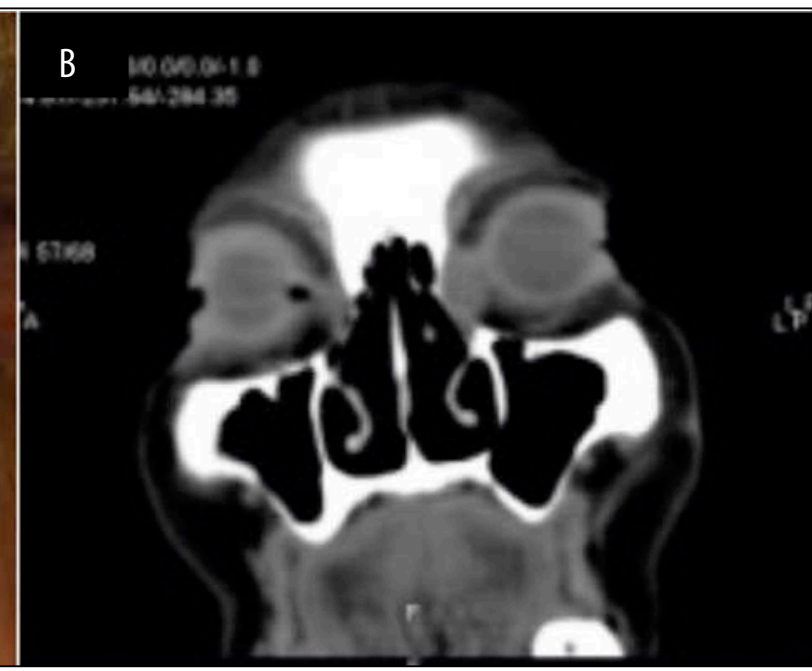

Figure 7 A. Swelling and redness tumefaction in the left eye inner corner; B. Cranio-facial CT-scan, coronal slice, showing a well-circumscribed, centred lesion on the left lacrimal sac 
In this case, the lacrimal sac was exposed by removing with the drill the covering bone. The incision revealed purulent secretions which were suctioned. A drainage tube (8ch urinary catheter, $2.66 \mathrm{~mm}$ in diameter) was inserted to maintain a patent lacrimal pathway and it was kept in place for 11 days.

Patient's evolution was favourable for 12 months, when the patient presented for left epiphora associated with inflammation of the left eye inner corner. After treating the acute dacryocystitis episode with antibiotics therapy, the surgical re-intervention was decided, this time by external approach. The lacrimal sac presented adhesions and stenosis, and the decision was to excise it (Figure 8). The probe used for the catheterization of the superior lacrimal point

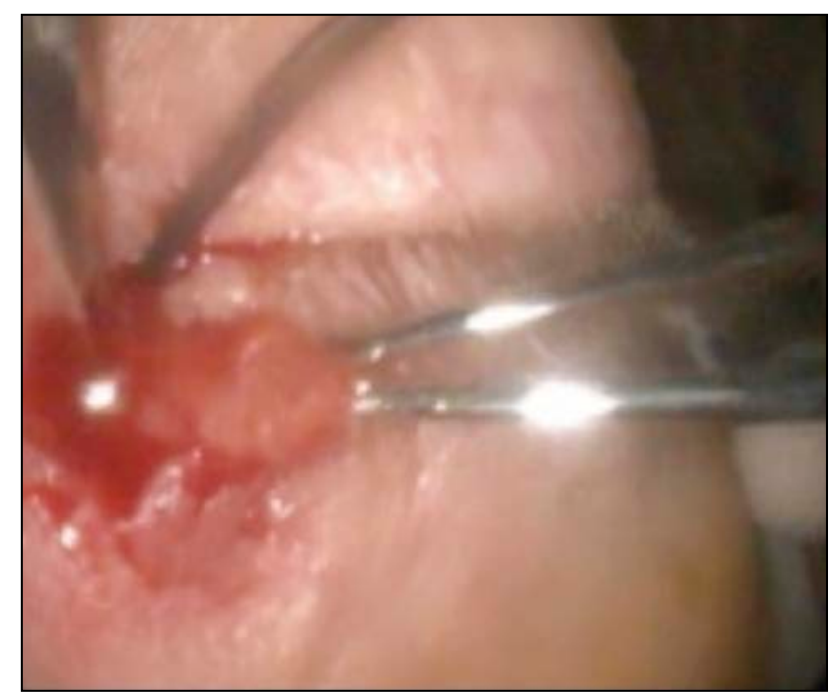

Figure 8 Intraoperatory view - excision of the left lacrimal sac stopped at the upper lacrimal duct, thus we performed only the catheterization of the lower duct with a silicone stent (Figure 9). After passing through the lower lacrimal duct, the stent was introduced through a venous catheter and inserted through the nasal bone into the left nasal fossa. The catheter was anchored and sutured subcutaneously with one end in the inner corner of the left eye, while the other end was exteriorized into the nasal cavity (Figure 10).

The catheter was suppressed 30 days after surgery, while the silicone stent was kept in place for 30 more days, being sutured to the lower eyelid.

The follow-up was made after 4 months and the evolution was favourable.

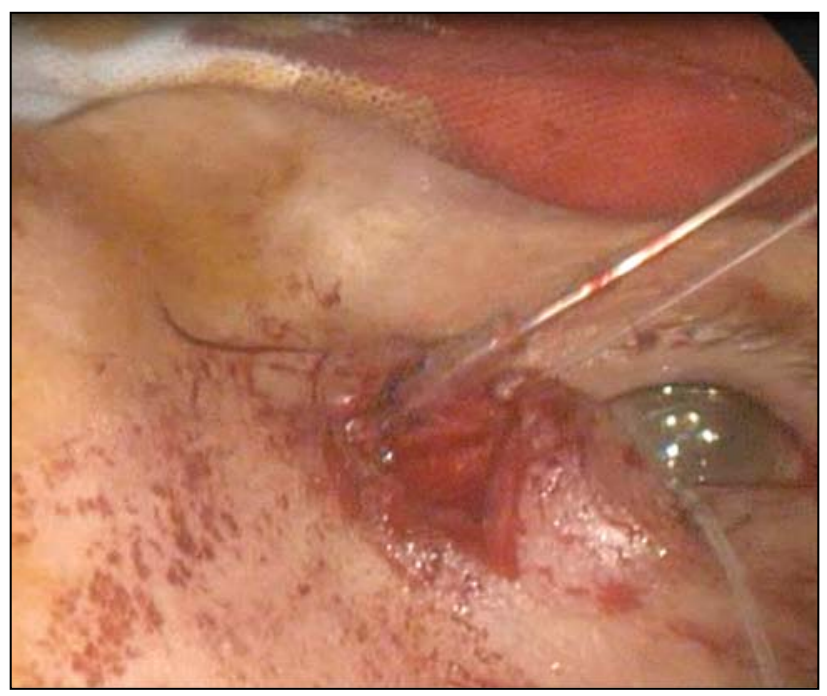

Figure 9 Catheterization of the lacrimal duct

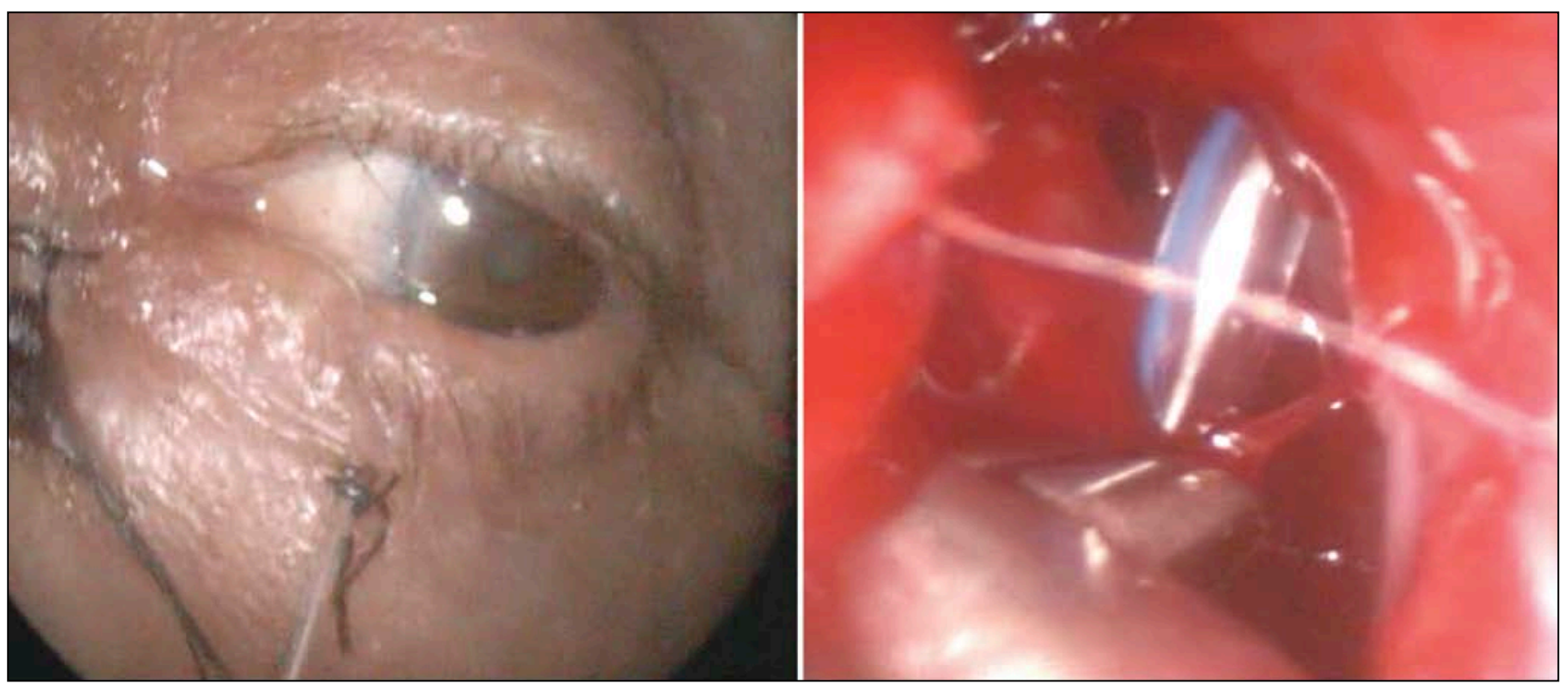

Figure 10 Intraoperatory view - the catheter anchored and sutured subcutaneously with one end in the inner corner of the left eye, while the other end was exteriorized into the nasal cavity 
The second case is that of a 35-year-old female patient who presented for right eye inflammation associated with chronic recurring epiphora and a persistent redness of the right medial canthus. The clinical evaluation revealed a painless swelling of the right lacrimal sac, whose pressure highlights a discharge of mucopurulent material through the lower punctum (Figure 11). The axial MRI showed the characteristics of a fluid, cystic lesion, rounded, homogeneous in the right side in T2 (bright) views (Figure 12).

In this case, we performed a wide excision of the lacrimal crest with Kerrison's forceps and the drill. The lacrimal sac was widely exposed and we created a large marsupialized lacrimal sac from the preserved mucosal flaps. A bicanaliculonasal silicone stent was

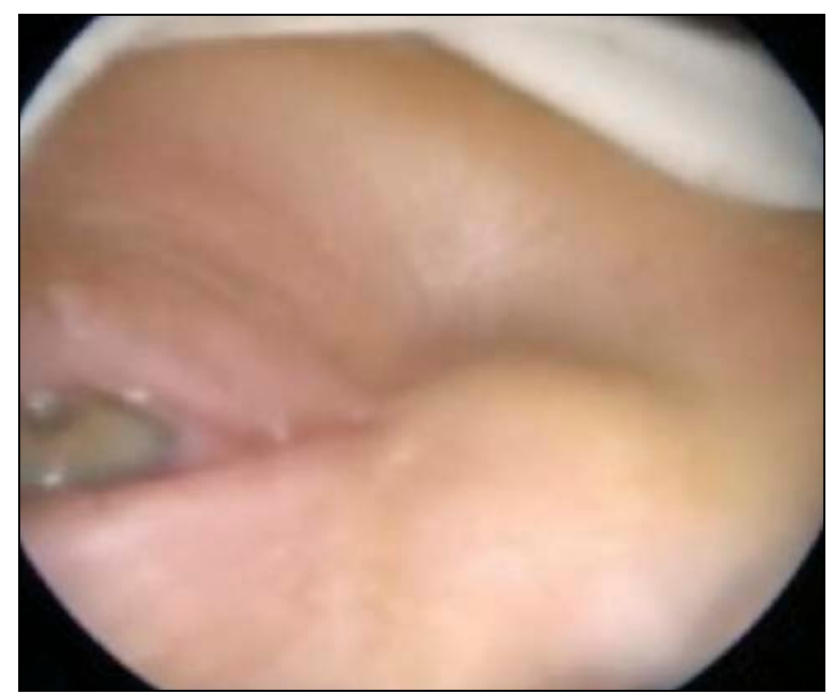

Figure 11 Swelling of the right lacrimal sac
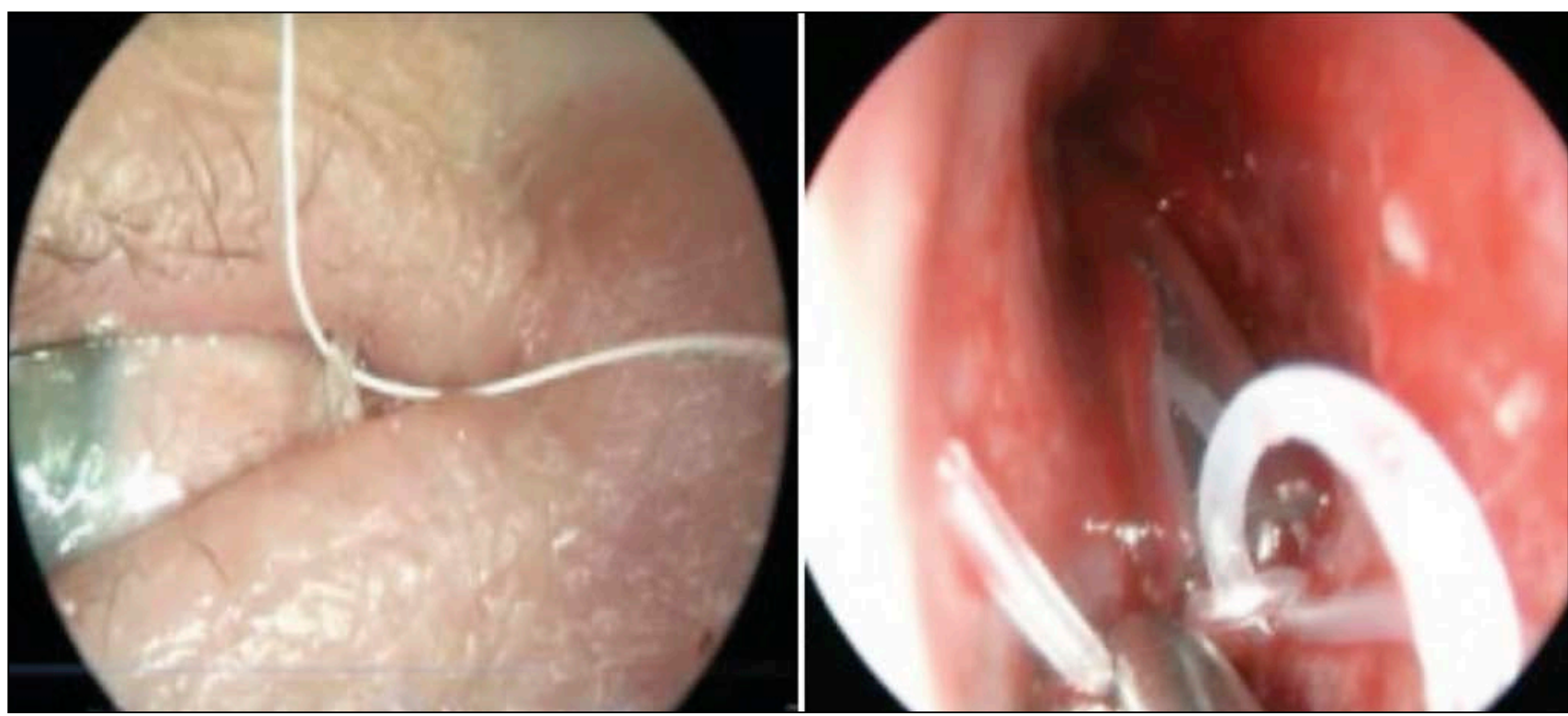

placed, and it was maintained for 45 days (Figure 13).

The patient presented a favourable evolution 6 months after the surgery.

The third case presented is a 75-year-old female patient with swelling and redness tumefaction in the left medial canthus and associated fistula through which pus was draining (Figure 14). The axial unenhanced CT scan section in bony windows revealed a well-defined water-density rounded lesion compatible with a cyst, in the left lacrimal sac, abutting the internal aspect of the globe. The cyst probably arose from the glands of Wolfring (Figure 15).

The Jones test was negative, signifying the obstruction of the left lacrimal common duct. For this reason, in conjunction with the existing fistula, we performed

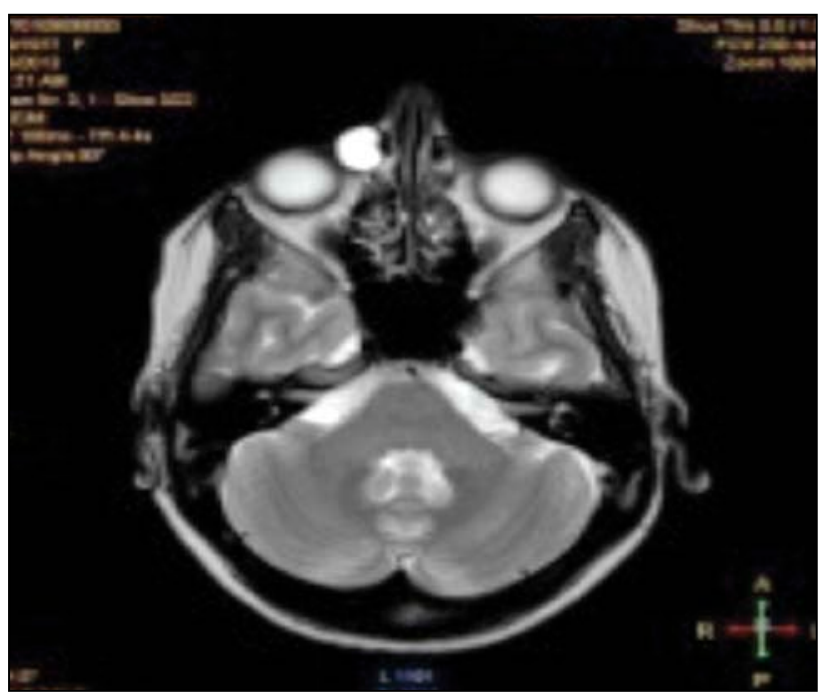

Figure 12 Cranio-facial MRI (T2), axial slice - fluid, cystic lesion on the right lacrimal sac

Figure 13 Intraoperatory view - bicanaliculonasal silicone stent 


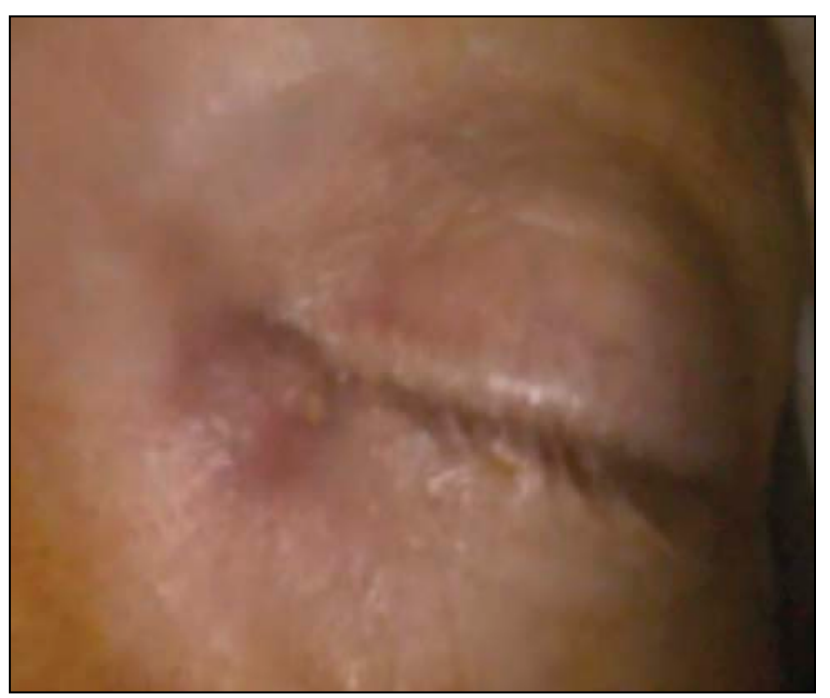

Figure 14 Swelling in the medial canthus of the eye associated with a fistula and pus drainage

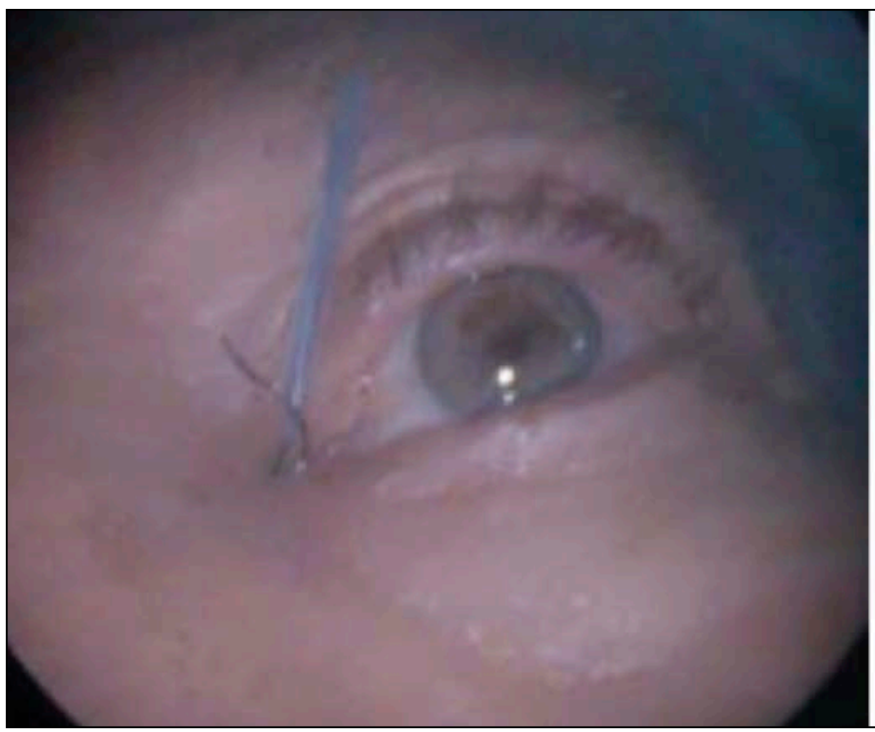

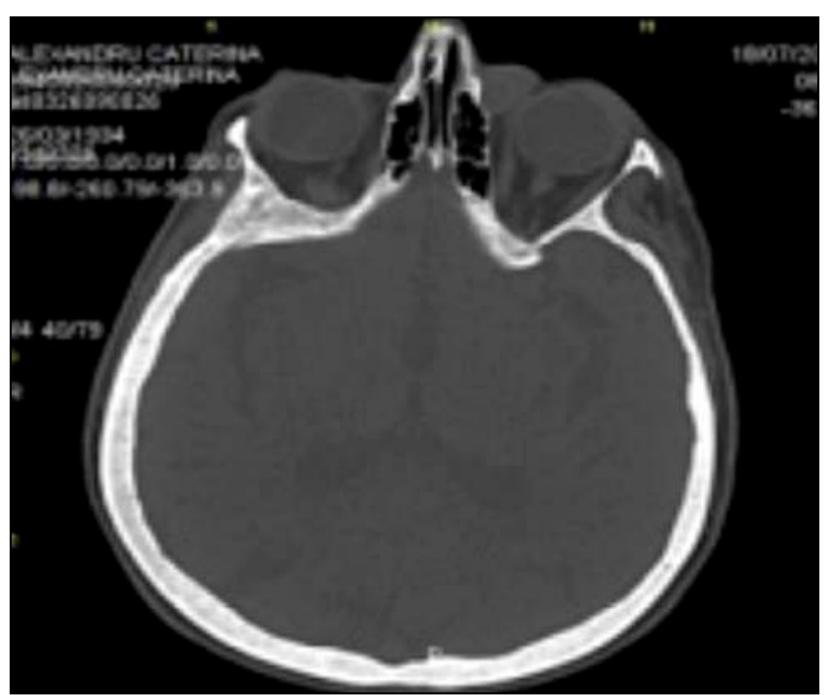

Figure 15 CT scan, axial slice - well-defined water-density rounded lesion compatible with a cyst in the left lacrimal sac

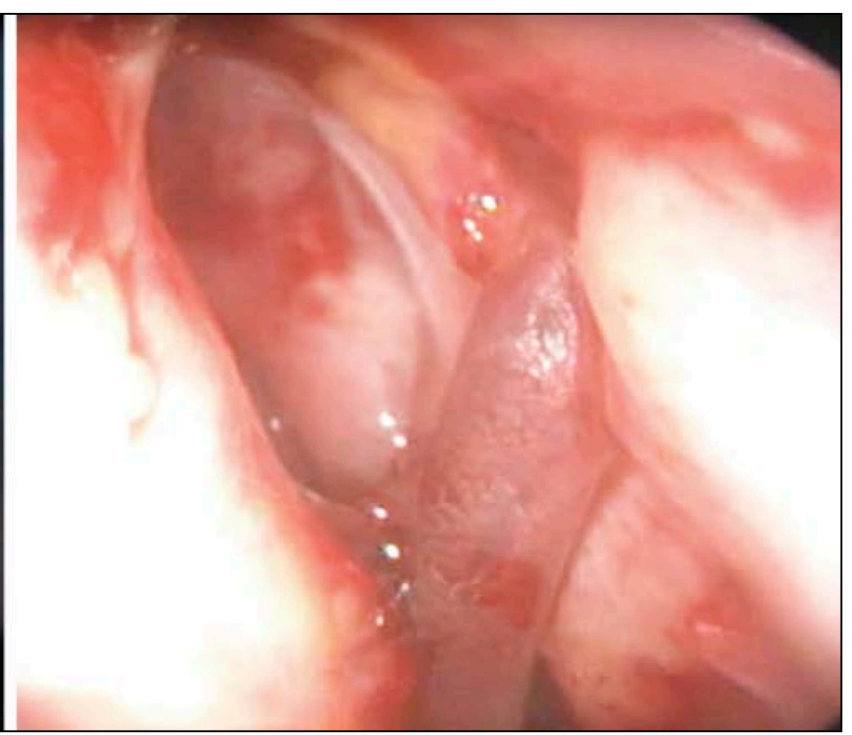

Figure 16 Permanent communication between the caruncular region and nasal cavity through a venous catheter

a laco-dacryo-rhinostomy ${ }^{5}$ that established a permanent communication between the caruncular region and nasal cavity through a venous catheter. The tube was passed through the lacrimal sac to maintain it permeable into the nasal fossa (Figure 16). The main complications involve the biotolerance of this tube ${ }^{5,6}$, but our patient tolerated it and removal of the tube was made after 30 days. Follow-up was made after 5 months and the patient had a favourable evolution.

\section{DISCUSSIONS}

Dacryocystitis is an infection of the lacrimal sac, appeared secondary to the obstruction of the nasolacrimal duct at the junction of the lacrimal sac. It causes pain, redness, epiphora, swelling over the lacrimal sac, and its pressure will result in reflux of mucopurulent material through the lower punctum.

The differential diagnosis has to be made with certain pathologies like: orbital or facial cellulitis (in this case discharge cannot be expressed from the punctum), acute ethmoid or frontal sinusitis, dacryocystocele, which is characteristic in paediatric patients.

The diagnosis is clinical and paraclinical. The paraclinical investigations that can be made are represented by: dye disappearance test, Jones tests I and II, probing and irrigation, dacryocystography (DCG) or dacryoscintigraphy (DSG). The CT- or MRI-DCG can determine if an anatomic obstruction exists within the outflow system, where the obstruction occurs, and gives excellent anatomic details, being of great help 
when structural abnormalities are suspected ${ }^{7}$. On the other hand, the DSG performed with technetium- $99 \mathrm{~m}$ pertechnetate or technetium-99m-labeled sulfur colloid has a low resolution and lack of anatomical details $^{8,9}$. In our cases, we used the Jones test, probing and irrigation associated with a cranio-facial CT or MRI scan.

The treatment of chronic dacryocystitis is surgical, represented by external or endoscopic dacryocystorhinostomy (DCR). There are a lot of controversies regarding the best standard method of treatment for chronic dacryocystitis. The external DCR was considered the "gold-standard" procedure in the treatment of chronic dacryocystitis at the beginning of the century. Its main advantage is the direct visualization of the lacrimal sac and the surrounding anatomical structure, but with the risk of potential injury of the canthal structures, cerebrospinal fluid lick and functional interference with the physiological action of the lacrimal pump $p^{10,11}$.

The endoscopic DCR, with or without a stent, consists in the creation of a fistulous tract between the lacrimal sac and the nasal fossa. The primary benefit of the endoscopic approach is the lack of skin scarring, the direct inspection of the lacrimal sac. Considering the situation, any endoscopic approach can be converted in an external one.

Over the years, there have been controversies regarding the use of stents to maintain the patency of the communication between the lacrimal sac and the nasal cavity. The first to introduce the silicon stent was Gibbs in $1988^{12}$.

In one comparative study, performed in 2009, Kakkar showed that results of endoscopic DCR with and without stent are almost equal ${ }^{13}$. Studies reported by Acharaya et al. ${ }^{14}$ and Harvinder et al. ${ }^{15}$ had the same results. At the same time, Unlu et al. did not find a significant difference in success between stent DCR compared to non-stent $\mathrm{DCR}^{16}$.

Dortzbach et al. showed that silicone intubation is not without complications, the most commonly being the biotolerance of this tube ${ }^{17}$.

In our opinion the endoscopic technique, with or without stenting, offers the advantage of a simple procedure performed by ENT doctors with minimal risks. The procedure facilitates the use of different types of stents. Stenting is important for maintaining stable the permeability of the lacrimal pathways especially when relapses occur.

\section{CONCLUSIONS}

The endoscopic DCR, with its different particularities, is a safe surgical procedure with a low rate of complications, being the treatment of choice for the treatment of nasolacrimal duct obstruction. In the pre- sented cases we adapted the surgical techniques, endoscopic and external approach with and without stenting, considering the particularities of the cases and the instruments and investigation possibilities we had.

From our own experience we can conclude that endoscopic DCR can be successfully used in case of lacrimal sac abscess or lacrimal sac fistulas. However, the knowledge of the intranasal anatomy and appropriate endoscopic training are required for this type of nasal endoscopic surgery.

\section{REFERENCES}

1. Caldwell G.W. - Two new operations for obstruction of the nasal duct, with preservation of the canaliculi, and with an incidental description of a new lacrimal probe. Am J Ophthalmol., 1893;10:189-193.

2. Tarbet K.J., Custer P.L. - External dacryocystorhinostomy: surgical success, patient satisfaction, and economic cost. Ophthalmology, 1995;102:1065-1070.

3. Yung M.W., Hardman-Lea S. - Analysis of the results of surgical endoscopic dacryocystorhinostomy: effect of the level of obstruction. Br J Ophthalmol., 2002;86(7):792-4.

4. Durvasula V., Gatland D.J. - Endoscopic dacryocystorhinostomy: longterm results and evolution of surgical technique. J Laryngol Otol., 2004;118:628-632.

5. Ducasse A. - Les voies lacrymales. Societe Francaise d'Ophthalmologie, Paris, 2006.

6. Dortzbach R.K., France T.D., Kushner B.J., Gonnering R.S. - Silicone intubation for obstruction of the nasolacrimal duct in children. Am J Ophthalmol., 1982;94:585-90.

7. Ewing A.E. - Roentgen ray demonstration of the lacrimal abscess cavity. Am J Ophthalmol., 1909;24:1.

8. Rossomondo R.M., Carlton W.H., Trueblood J., et al. - A new method of evaluating lacrimal drainage. Arch Ophthalmol., 1972; 88:523-525.

9. Wearne M.J., Pitts J., Frank J., et al. - Comparison of dacryocystography and lacrimal scintigraphy in the diagnosis of functional nasolacrimal duct obstruction. Br J Ophthalmo., 1999;83:1032-5.

10. Karim R., Ghabrial R., Lynch T.F., Tang B. - A comparison of external and endoscopic endonasal dacryocystorhinostomy for acquired nasolacrimal duct obstruction. Clinical Ophthalmology, 2011;5:979-989.

11. Shun-Shin G.A., Thurairajan G. - External dacryocystorhinostomy - an end of an era? Br J Ophthalmol., 1997;81:716-717.

12. Gibbs D.C. - New probe for the intubation of lacrimal canaliculi with silicone rubber tubing. Br J Opthalmol., 1967;51 (3):1988.

13. Kakkar V., Chugh J.P., Sachdeva S., et.al. - Dacryocystorhinostomy With And Without Silicon Stent: A Comparative Study. Internet J Otolaryngol., 2008:9:1.

14. Acharya K., Pradhan B., Thapa N. - Comparison of outcome following endoscopic dacryocystorhinostomy with external dacryocystorhinostomy. Nepalese J ENT Head and Neck Surgery, 2011:2(2):2-3.

15. Harvinder S., Rosalind S., Philip R. - Powered Endoscopic Dacryocystorhinostomy with Mucosal Flaps Without Stenting. Med J Malaysia, 2008;63(3):237-238.

16. Unlu H.H., Toprak B. - Comparison of surgical outcomes in endoscopic dacryocystorhinostomy with or without silicon intubation. Ann Otol Rhinol Laryngol., 2002;111(8)-09.

17. Dortzbach R.K., France T.D., Kushner B.J., Gonnering R.S. - Silicone intubation for obstruction of the nasolacrimal duct in children. Am J Ophthalmol., 1982;94:585-90. 